\title{
Aislamiento y caracterización de un péptido antibacteriano del veneno de Centruroides margaritatus
}

\section{Isolation and characterization of antibacterial peptide from Centruroides margaritatus venom}

\author{
Carlos Rivera, Lidia Flores, Carmen Pantigoso y Enrique Escobar
}

Laboratorio de Bioquímica y Genética Molecular. Facultad de Ciencias Biológicas. Universidad Nacional Mayor de San Marcos. Apartado 10058, Lima 11, Perú. Email Enrique Escobar: eescobarg@unmsm.edu.pe
Trabajo presentado a la XVIII Reunión Científica del Instituto de Investigaciones en Ciencias Biológicas Antonio Raimondi, "200 años del nacimiento de Charles Darwin y el 150 aniversario de la publicación de aniversa da publicacion de On the Origin of Species by 19 al 21 de agosto de 2009 .

Publicado impreso: 20/10/2010 Publicado online: 29/09/2010

\section{Resumen}

En este trabajo se ha aislado y caracterizado parcialmente un péptido con actividad antibacteriana del veneno del escorpión Centruroides margaritatus (Gervais, 1841) (Scorpiones: Buthidae). Este péptido fue aislado a partir de $50 \mathrm{mg}$ de veneno crudo, y la purificación fue inicialmente realizada por cromatografía de intercambio iónico en CM-Sephadex C-25, obteniéndose siete picos de proteína. El pico III de esta separación fue purificado por cromatografía de filtración en Sephadex G-75, obteniéndose dos picos de proteína, de los cuales el segundo mostró ser el péptido antibacteriano. Este péptido representa aproximadamente el $3 \%$ de la proteína total del veneno y por PAGE-SDS, se determinó que tiene un peso molecular de 7,3 kDa. El péptido antibacteriano inhibe el crecimiento de Bacillus cereus, Staphylococcus aureus, Pseudomonas aeruginosa y Serratia marcencens, en microplacas con medio mínimo de Davies, pero los ensayos en agar Müller-Hinton, no mostraron halos de inhibición significativos, concluyéndose que el péptido tiene actividad bacteriostática pero no bactericida. Además, no mostró acción sobre Enterococcus faecalis, Escherichia coli, Salmonella choleraesuis y Klebsiella pneumoniae. El péptido antibacteriano también fue capaz de inhibir el crecimiento de Aspergillus níger y Candida albicans durante 48 horas, pero no tiene actividad hemolítica sobre eritrocitos humanos.

Palabras claves: escorpión, antibacteriano, péptido

\section{Abstract}

In this work, from the venom of Centruroides margaritatus (Gervais, 1841) (Scorpiones, Buthidae), one peptide with antibacterial activity was isolated and characterized. This peptide was isolated from $50 \mathrm{mg}$ of whole venom, the purification was initially performed by chromatography on CM-Sephadex C-25 obtaining protein peaks seven. The peak III of this separation was purified by gel filtration on Sephadex G-75, yielding protein peaks two, the second of which proved to be the antibacterial peptide. This peptide represents about $3 \%$ of whole venom protein and by PAGE-SDS, was determinate it has $7,3 \mathrm{kDa}$ of molecular weight. The antibacterial peptide inhibits the growth of Bacillus cereus, Staphylococcus aureus, Pseudomonas aeruginosa y Serratia marcencens, in microplates with minimal media Davies, but in assays in Muller-Hinton agar, showed no significant inhibition halos; concluding that peptide has bacteriostatic activity but not bactericidal activity. In addition has not activity on Enterococcus faecalis, Escherichia coli, Salmonella choleraesuis and Klebsiella pneumoniae. Antibacterial peptide also inhibited the growth of Aspergillus niger and Candida albicans during 48 hours, but has not hemolytic activity.

Keywords: scorpion, antibacterial, peptide

\section{Introducción}

Los antibióticos son muy utilizados para combatir infecciones bacterianas; sin embargo, el fenómeno de resistencia bacteriana ha limitado su uso y ha generado la necesidad de hallar nuevos agentes antibacterianos.

En diversas secreciones de organismos se han hallado péptidos con actividad antimicrobiana que pueden actuar sobre bacterias, virus, protozoarios, levaduras y hongos (Csordas \& Michl 1969, Steiner et al. 1981, Bulet et al. 1999, Broekaert et al. 1995, Nicolas \& Mor 1995, Ganz y Lehrer 1998, Hoffmann et al. 1999).

La mayoría de estos péptidos son de naturaleza básica, tienen pesos moleculares entre 2 y $5 \mathrm{kDa}$ y son capaces de formar poros en la membrana celular afectando la permeabilidad y fisiología celular; además, muchos de ellos tienen actividad hemolítica (Torres-Larios et al. 2000, Sitaram \& Nagaraj 2002).

En venenos de escorpiones se han encontrado péptidos capaces de formar poros en las membranas de algunos microorganismos y dańarlas, produciendo de esta manera un efecto antimicrobiano. La mayoría de estos péptidos carecen de cisteína y son de naturaleza $\alpha$-helicoidal, mientras que otros contienen cisteína y puentes disulfuro. Algunos de estos péptidos son la parabutoporina de Parabuthus schlechteri (Verdonck et al. 2000), la scorpina de Pandinus imperator (Conde et al. 2000), la hadrurina de Hadrurus aztecus (Torres-Larios et al. 2000), la IsCTs de Opisthacanthus madagascariensis (Dai et al. 2001 y 2002) y las pandininas 1 y 2 de Pandinus imperator (Corzo et al. 2001).

En algunos venenos de escorpiones del Perú no sólo se han aislado algunas toxinas con acción sobre roedores e insectos (Escobar et al. 2002, Escobar et al. 2003, Velásquez \& Escobar 2004), sino además también se han identificado algunos péptidos antibacterianos (Escobar et al. 2008).

En general, estos péptidos forman parte del sistema inmune y actúan como un mecanismo de defensa contra microorganismos invasores, y su estudio es importante por su potencial uso en el diseńo de principios activos contra infecciones bacterianas resistentes a antibióticos.

\section{Material y métodos}

Veneno de escorpión.- Se colectaron escorpiones adultos de ambos sexos de Centruroides margaritatus (Gervais, 1841) (Scorpiones: Buthidae), en la provincia de Zarumilla (Tumbes). En el laboratorio, los escorpiones fueron mantenidos aislados en cubetas plásticas de $10 \times 6 \times 10 \mathrm{~cm}$ con agua ad libitum y alimentados quincenalmente con grillos y arañas (Candido y Lucas 2004). El veneno fue obtenido por estimulación eléctrica con 22 voltios y se desecó al vacío, conservándose en refrigeración hasta su uso. 


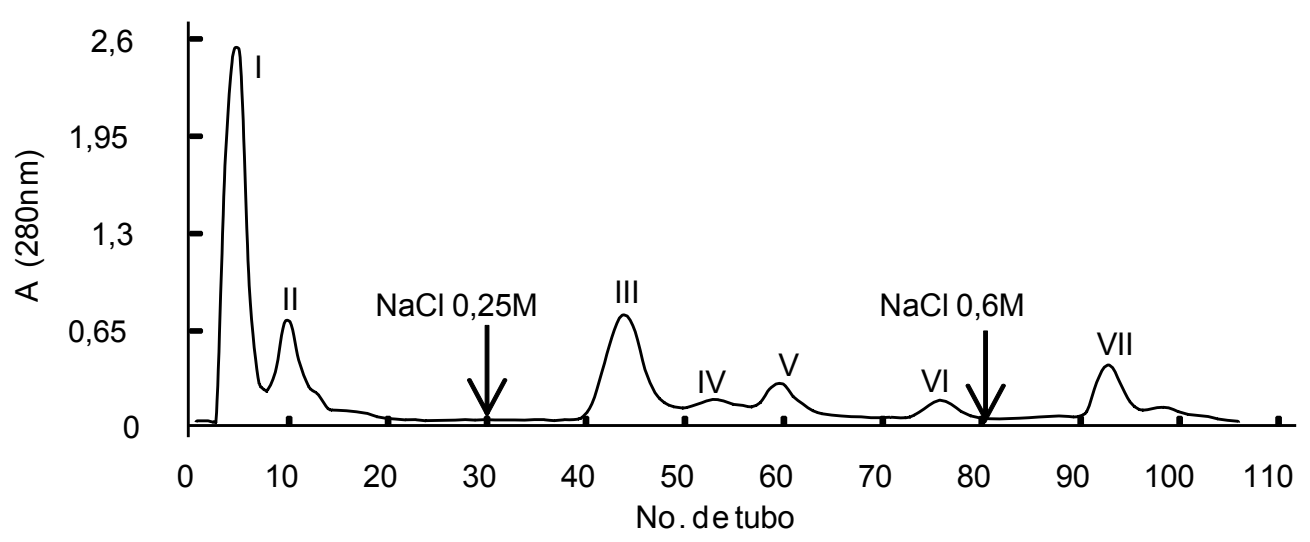

Figura 1. Perfil cromatográfico del veneno de Centruroides margaritatus en CM-Sephadex C-25. Se obtuvieron 7 picos (del I a I VII). Con excepción del primer pico, todos los demás mostraron actividad antibacteriana, siendo la asociada al pico III la que se continuó purificando.

Cepas bacterianas.- Gram positivas: Bacillus cereus ATCC 14579, Enterococcus faecalis y Staphylococcus aureus ATCC 25923. Gram negativas: Escherichia coli ATCC 25922, Pseudomona aeruginosa ATCC 15442, Salmonella choleraesuis ATCC 14028, Klebsiella pneumoniae y Serratia marcencens.

Hongos.- Candida albicans ATCC 10231 y esporas de Aspergillus niger ATCC 9372.

Cuantificación de proteína.- Fue estimada por absorción de luz ultravioleta a $280 \mathrm{~nm}$ (Warburg \& Christian 1941).

Fraccionamiento del veneno.- $50 \mathrm{mg}$ del veneno de C. margaritatus fueron disueltos en $2 \mathrm{~mL}$ de buffer acetato de amonio $0,05 \mathrm{M}$ a pH 7 , y los restos insolubles fueron eliminados por centrifugación a 10000 rpm durante 15 minutos. Del sobrenadante, se aplicó 1,6 mL a una columna de CM-Sephadex C-25 $(1,1 \times 17,4 \mathrm{~cm})$ equilibrada con el mismo buffer y las proteínas retenidas fueron eluidas con el buffer conteniendo $\mathrm{NaCl} 0,25 \mathrm{M}$ y 0,6M. Para continuar la purificación del péptido antibacteriano de interés, se realizó una cromatografía de filtración en Sephadex G-75 $(1,1 \times 33 \mathrm{~cm})$ también calibrada con buffer acetato de amonio $0,05 \mathrm{M}$ a pH 7 .

Electroforesis en gel de poliacrilamida.- La pureza y el peso molecular del péptido aislado se evaluó por electroforesis en gel de poliacrilamida en condiciones denaturantes con dodecil sulfato de sodio (PAGE-SDS) de acuerdo al método de Schägger y Von Jagow (1987). Como proteínas estándares se usaron lisozima $(14,3 \mathrm{kDa})$ y aprotinina $(6,5 \mathrm{kDa})$. La electroforesis se realizó a voltaje constante $(100 \mathrm{~V})$ durante 1,5 horas. La naturaleza básica del péptido se verificó por electroforesis en gel de poliacrilamida en condiciones nativas, según el método de Reisfeld et al. (1962). En este sistema se empleó voltaje constante $(120 \mathrm{~V})$ durante 5 horas.

Actividad antibacteriana.- La actividad antibacteriana se ensayó en microplacas de 96 pocillos, en los que se colocó 90 $\mu \mathrm{L}$ del cultivo bacteriano en medio mínimo de Davies (con una absorbancia inicial a $600 \mathrm{~nm}$ de 0,02$)$ y $10 \mu \mathrm{L}$ de la fracción respectiva. Luego de 24 horas a $37^{\circ} \mathrm{C}$ se determinó el crecimiento bacteriano por la turbidez desarrollada en cada pocillo. El efecto inhibidor se determinó por la ausencia de turbidez.

El efecto bactericida se evaluó en placas petri con medio enriquecido (agar Müller-Hinton), donde se sembraron cultivos bacterianos en la escala dos de Mc Farland, por diseminación, según el protocolo estándar. Luego se colocaron discos de papel filtro impregnados con el péptido antimicrobiano (hasta $10 \mu \mathrm{g}$ ) y se incubó a $37^{\circ} \mathrm{C}$ por 24 horas. Este ensayo se realizó para cada bacteria y por cuadruplicado. La actividad bactericida se determinó por la aparición de halos de inhibición alrededor del cultivo bacteriano.

Actividad antimicótica.- La actividad sobre $A$. niger, se evaluó en microplacas con pocillos, mezclando $10 \mu \mathrm{L}$ de una suspensión de $2 \times 10^{5}$ esporas $/ \mathrm{mL}$ en agua destilada, $70 \mu \mathrm{L}$ de Caldo Saboraud conteniendo $250 \mathrm{ppm}$ de cloranfenicol y $20 \mu \mathrm{L}$ del péptido antimicrobiano (Moerman et al. 2002). Se incubó a temperatura ambiente y el crecimiento se evaluó a las 24,48 , 72 y 120 horas.

En el caso de C. albicans, la inhibición del crecimiento también se midió en microplacas con pocillos, mezclando $80 \mu \mathrm{L}$ de un cultivo celular en fase logarítmica diluido con caldo Saboraud conteniendo $250 \mathrm{ppm}$ de cloranfenicol, hasta una absorbancia a $600 \mathrm{~nm}$ de 0,002 , más $20 \mu \mathrm{L}$ del péptido antibacteriano. Todo se incubó a temperatura ambiente y la evaluación se realizó a las 24, 48, 72 y 120 horas.

Actividad hemolítica.- Se ensayó sobre glóbulos rojos humanos. Nueve mililitros de sangre se mezclaron con $1 \mathrm{~mL}$ de citrato de sodio 3,8\% y se centrifugó a $3000 \mathrm{rpm}$ durante 15 minutos. Se eliminó el sobrenadante y el paquete de glóbulos rojos se lavó 3 veces con buffer fosfato $0,05 \mathrm{M}$ con $\mathrm{NaCl} 0,9 \%$ a pH 7,4. Finalmente de una suspensión al $0,5 \%$, se tomó 0,9 $\mathrm{mL}$ y se incubó con $0,1 \mathrm{~mL}$ de la fracción respectiva durante 1 hora a $37^{\circ} \mathrm{C}$, luego de lo cual se evaluó la hemólisis producida.

\section{Resultados}

Separación del péptido y actividad antibacteriana.- Al pasar el veneno crudo de Centruroides margaritatus por la columna de CM-Sephadex C-25, se obtuvo un perfil cromatográfico con siete picos proteicos, de los cuales los dos primeros eluyeron con el buffer inicial de corrida; $\operatorname{los} 4$ picos siguientes fueron eluidos con el buffer conteniendo $\mathrm{NaCl} 0,25 \mathrm{M}$ y el último pico se obtuvo con $\mathrm{NaCl} 0.6 \mathrm{M}$ en el mismo buffer (Fig. 1).

$\mathrm{Al}$ evaluar la actividad antimicrobiana se encontró que, con excepción del primer pico, todos los demás inhibieron el crecimiento de ciertas cepas bacterianas. En particular el tercer pico, el cual tuvo el mayor porcentaje de proteína (20\%), inhibió el crecimiento de las bacterias Bacillus cereus, Staphylococcus aureus, Pseudomonas aeruginosa y Serratia marcencens. Este efecto se detectó con 3,84 $\mu \mathrm{g}$ de proteína. 
Tabla 1. Acción del péptido antibacteriano sobre algunas bacterias.

\begin{tabular}{cc}
\hline Bacteria & Actividad \\
\hline Gram-positiva & + \\
Bacillus cereus & + \\
Staphylococcus aureus & - \\
Enterococcus faecalis & \\
Gram-negativas & + \\
Pseudomona aeruginosa & + \\
Serratia marcencens & - \\
Escherichia coli & - \\
Salmonella choleraesuis & - \\
Klebsiella pneumoniae &
\end{tabular}

Al pasar este pico por la columna de Sephadex G-75, se obtuvieron dos picos de proteína (Fig. 2); de los cuales, el segundo mostró actividad antimicrobiana sobre las mismas cepas de bacterias indicadas (Tabla 1).

$\mathrm{Al}$ evaluar la actividad bactericida en placas petri con agar Müller-Hinton, se encontró que el péptido antibacteriano produjo un ligero halo de inhibición de $4 \mathrm{~mm}$ sólo sobre $S$. aureus, y no afectó a Bacillus subtilis, Pseudomonas aeruginosa y Serratia marcencens. Este resultado indica que el péptido posee un efecto bacteriostático, más no bactericida.

Electroforesis en gel de poliacrilamida.- La PAGE-SDS del péptido antibacteriano, según el método de Schägger y Von Jagow (1987), mostró la presencia de una sola banda proteica de 7,3 KDa de peso molecular. Adicionalmente, la electroforesis en condiciones nativas mostró que el péptido corresponde a una banda proteica de migración catódica (Fig. 3).

Actividad antimicótica.- El péptido antimicrobiano inhibió totalmente el desarrollo de Candida albicans y Aspergillus niger hasta las 48 horas de evaluación. Sin embargo, a las 120 horas de evaluación se observó un desarrollo en los cultivos.

Actividad hemolítica.- El péptido aislado no mostró actividad hemolítica.

\section{Discusión}

Debido a que los venenos de escorpiones tienen un alto contenido de péptidos de naturaleza básica, y todos los péptidos antimicrobianos hallados en estos venenos también lo son, la cromatografía de intercambio catiónico permite la separación

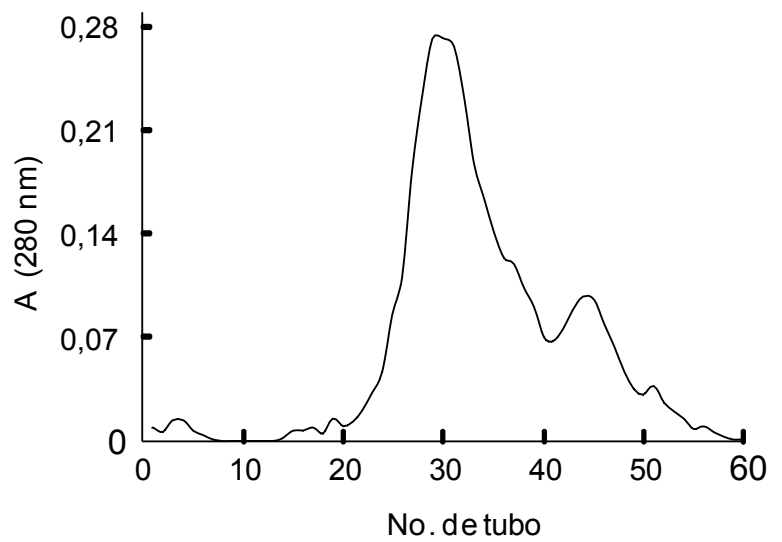

Figura 2. Al pasar el tercer pico de proteína del primer paso de purificación por la columna de Sephadex G-75, se obtuvieron dos picos de proteína, de los cuales el segundo mostró actividad antibacteriana.

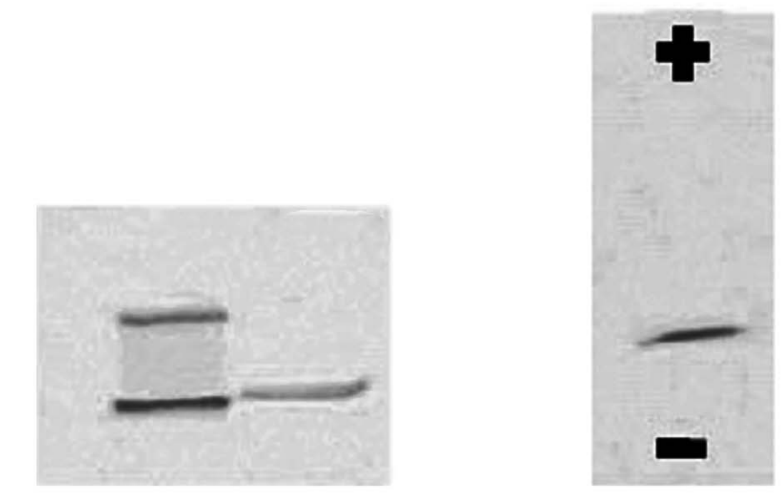

Figura 3. A la izquierda se muestra la PAGE-SDS del péptido antibacteriano: el primer carril contiene las proteínas estándares lisozyma $(14,3 \mathrm{kDa})$ y aprotinina $(6,5 \mathrm{kDa})$, mientras que en el segundo carril se tiene el péptido antibacteriano $(7,3 \mathrm{kDa})$. A la derecha se muestra el patrón electroforético en condiciones nativas del péptido, observándose una banda proteica con migración hacia el cátodo.

de dichos péptidos. Así por ejemplo en algunos venenos de escorpiones se han purificado diversos péptidos mediante una combinación de cromatografía de intercambio iónico y cromatografía de filtración y/o HPLC (Conde et al. 2000, Torres-Larios et al. 2000).

En este trabajo mediante dos pasos cromatográficos, uno de intercambio catiónico y otro de filtración, se ha logrado aislar un péptido antimicrobiano del veneno de $C$. margaritatus. Cuando el veneno crudo de $C$. margaritatus se pasó por la columna de CM Sephadex C-25, se obtuvieron 7 picos proteicos, siendo notable el hecho de que 6 de ellos tienen actividad antibacteriana. Sin embargo sólo la actividad antibacteriana asociada al pico 3 fue estudiada y adicionalmente purificada en Sephadex G-75, donde se obtuvo un perfil con dos picos proteicos: el primero mas grande que el segundo. En este segundo pico se detecto la actividad antibacteriana pero sólo localizada en el pico mismo y la fracción siguiente.

Estos resultados más los obtenidos de la electroforesis en condiciones denaturantes, permiten deducir que luego del primer paso de purificación en la columna de CM Sephadex C-25, el péptido antibacteriano de interés tiene algunos contaminantes proteicos de mayor peso, que son separados luego de la cromatografía de filtración en Sephadex G-75. Así, luego del segundo paso de purificación, el primer pico que eluye contiene las proteínas contaminantes de mayor tamańo, mientras que el péptido antibacteriano sale en el segundo pico.

Los péptidos con actividad antimicrobiana, obtenidos de venenos de escorpiones, son de bajo peso molecular, variando entre 1,5 y $8,3 \mathrm{kDa}$. Además todos los péptidos antimicrobianos que se han aislado de venenos de escorpiones son de naturaleza básica, y entre ellos se pueden mencionar las pandininas de Pandinus imperator (Corzo et al. 2001), la hadrurina de Hadrurus aztecus (Torres-Larios et al. 2000) y la parabutoporina de Parabuthus schleteri (Verdonck et al. 2000). El péptido aislado en este estudio también es de naturaleza básica, por ello a pH 7 interactúa mediante sus cargas positivas con las cargas negativas del CM Sepahdex C-25, y sólo se puede eluir al aplicar $\mathrm{NaCl}$ $0,2 \mathrm{M}$. Asimismo, su naturaleza básica queda en evidencia por su migración hacia el polo negativo en un campo eléctrico en condiciones nativas. 
La acción antibacteriana del péptido aislado, en los ensayos en microplacas con medio mínimo de Davies, fue evidente tanto sobre bacterias Gram-positivas (Bacillus cereus y Staphylococcus aureus), como Gram-negativas (Pseudomonas aeruginosa y Serratia marcencens). Sin embargo en los ensayos en placas petri con medio enriquecido (agar Müller-Hinton), no hubo ningún efecto inhibitorio en el crecimiento de las mismas bacterias, lo cual indica que este péptido tiene un efecto bacteriostático pero no bactericida. Otros péptidos de venenos de escorpiones también se caracterizan por inhibir el crecimiento de bacterias Gram-positivas y Gramnegativas, aunque algunos como el péptido IsCT aislado del veneno de Opisthacanthus madagascariensis y las pandininas de Pandinus imperator, tienen acción preferencial sobre bacterias Gram-positivas (Dai et al. 2001, Corzo et al. 2001).

En relación a los resultados de la acción antimicótica, el péptido aislado fue capaz de inhibir completamente el crecimiento de Aspergillus niger y Candida albicans durante 48 horas. Ya que a las 120 horas se observó un crecimiento de ambos microorganismos, se puede decir que el efecto antimicótico es temporal, pues el desarrollo se retarda pero no se inhibe definitivamente. A diferencia de otros péptidos antimicrobianos de venenos de escorpiones como la hadrurina, la pandinina 2 e IsCT, el péptido estudiado no es hemolítico.

Respecto al mecanismo de acción de estos péptidos, se ha propuesto que debido a su naturaleza catiónica, pueden interactuar por afinidad electrostática con la membrana plasmática de bacterias, hongos u otras células, y formar poros que dañan la permeabilidad celular (Hancock et al. 2006). Por otro lado el péptido antibacteriano llamado scorpina, aislado del veneno de Pandinus imperator, exhibe además un potente efecto inhibitorio sobre el desarrollo de los ookinetos y gametos de Plasmodium berghei (Conde et al. 2000).

\section{Literatura citada}

Broekaert W.F., F.R. Terras, B.P. Cammue \& R.W. Osborn. 1995. Plant defensins: novel antimicrobial peptides as components of the host defense system. Plant Physiol. 108, 1353-1358.

Bulet P., J. Hetru, J. Dimarcq \& D. Hoffmann. 1999. Antimicrobial peptides in insects; estructure and function. Development and Comparative Inmunology. 23: $329-344$.

Candido D. \& S. Lucas. 2004. Maintenance of scorpions of the genus Tityus Koch (Scorpiones, Buthidae) for venom obtention at Instituto Butantan, Sao Paulo, Brazil. J. Venom. Anim. Toxins incl. Trop. Dis. 10: 86-97.

Conde R., M. Zamudio, M.H. Rodríguez \& L.D. Possani. 2000. Scorpine, an anti-malaria and anti-bacterial agent purified from scorpion. FEBS Letters 471: 165-168.

Corzo G., P. Escoubas, E. Villegas, et al. 2001. Characterization of unique amphipathic antimicrobial peptides from venom of the scorpion Pandinus imperator. Biochem. J. 359, 35-45.

Csordas A. \& H. Michl. 1969. Primary structure of two oligopeptides of the toxin of Bombina variegata. Toxicon 7 (2) : 103-108.
Dai L., G. Corzo, H. Naoki, M. Andriantsiferana \& T. Nakajima. 2002. Purification, structure-function analysis, and molecular characterization of novel linear peptides from scorpion Opisthacanthus madagascariensis. Biochem. Biophys. Res. Commun. 293, 1514-1522.

Dai L., A. Yasuda, H. Naoki, et al. 2001. IsCT a novel cytotoxic linear peptide from scorpion Opisthacanthus madagascariensis. Biochem. Biophys. Res. Commun. 286, 820- 825.

Escobar E., L. Velásquez \&. C. Rivera. 2003. Separación e identificación de algunas toxinas del veneno de Centruroides margaritatus (Gervais, 1841). Revista peruana de biología. $10(2): 217-220$.

Escobar E., L. Flores \& C. Rivera. 2008. Péptidos antibacterianos de los venenos de Hadruroides mauryi y Centruroides margaritatus. Rev. peru. biol. 15(1): 139-142.

Escobar E., C. Rivera, C., L. Tincopa \& D. Rivera. 2002. Purificación parcial de las toxinas H11, Hl2 y Hl3 del veneno del escorpión Hadruroides lunatus Koch, 1867. Revista peruana de biología. 9 (1) : 310 .

Ganz T. \& R.I. Lehrer. 1998. Antimicrobial peptides of vertebrates. Curr. Opin. Immunol. $10: 41-44$.

Hancock E. W., H. Jenssen \& P. Hamill. 2006. Peptide Antimicrobial Agents. Clinical Microbiology Review. 19(3): 491-511.

Hoffmann J. A., F. C. Kafatos, C. A. Janeway \& R.A. Ezekowitz. 1999. Phylogenetic perspectives in innate immunity. Science (Washington, D.C.) 284: 1313-1318.

Moerman L., S. Bosteels, W. Noppe, et al. 2002. Antimicrobial antifungal properties of $\alpha$-helical, cationic peptides in venom of scorpions from sourthen Africa.

Nicolas P. \& A. Mor. 1995. Peptides as weapons against microorganisms in the chemical defense system of vertebrates. Annu. Rev. Microbiol. 49: 277-304.

Reisfeld A., J. Lewis, \& F. Williams. 1962. Disk electrophoresis of basic proteins and peptides on polyacrylamide gels. Nature. $195: 281-283$.

Schägger H. \& G.V. Jagow. 1987. Tricine-Sodium Dodecyl SulfatePolyacrylamide gel Electrophoresis for the Separation of Proteins in the Range from 1 to $100 \mathrm{kDa}$. Analitical Biochemistry . 166: 368- 379.

Sitaram N. \& R. Nagaraj. 2002. Antimicrobial Peptides as Novel Therapeutic Agents to Combat Drug-Resistant Microbial Infections. Current Medicinal Chemistry - Anti-Infective Agents.1 (4): 413-430.

Steiner H., D. Hultmark, A. Engstrom, H. Bennich \& H.G. Boman, 1981. Sequence and specificity of two antibacterial proteins involved in insect immunity. Nature 292 (5820): 246-248. Natue (London) 292, 246-248.

Torres-Larios A., G.B. Gurrola, F.Z. Zamudio \& L.D. Possani. 2000. Hadrurin, a new antimicrobial peptide from the venom of the scorpion Hadrurus aztecus. Eur. J. Biochem. 267, 5023-5031.

Velásquez L. \& E. Escobar. 2004. Purificación y caracterización parcial de una toxina $(\mathrm{Hm} 3)$ del veneno de Hadruroides mauryi (Francke y Soleglad, 1980) (Scorpiones, Iuridae). Revista peruana de biología. 11 (2): 153-160.

Verdonck F., S. Bosteels, J. Desmet, et al. 2000. A novel class of poreforming peptides in the venom of Parabuthus schlechteri Purcell (Scorpions: Buthidae). Cimbebasia 16 (24) : 7-260.

Warburg O. \& W. Christian. 1941. Isolierung and Kristalisation der Garungs ferments enolase. Biochem. Z. Vol. 310 : 384-421. 